www.jmscr.igmpublication.org

Impact Factor 5.84

Index Copernicus Value: 83.27

ISSN (e)-2347-176x ISSN (p) 2455-0450

crossref DOI: https://dx.doi.org/10.18535/jmscr/v5i7.140

Journal Of Medical Science And Clinical Research

IGM Publication

An Official Publication of IGM Publication

\title{
Efficiency of Local Antiseptic solution on the Incidence of Surgical Site Infection after Inguinal Hernia repair - A Prospective Study in a Tertiary Rural Hospital
}

\author{
Authors \\ Shashirekha $\mathrm{CA}^{1}$, Karthik Hareen $\mathrm{TVK}^{2}$, Ravikiran $\mathrm{HR}^{3}$, Sukanya $\mathrm{M}^{4}$ \\ ${ }^{1}$ Assoc Professor, Dept of General Surgery, Sri DevrajUrs Medical College, Kolar \\ ${ }^{2}$ Post graduate, Dept of General Surgery, Sri Devraj Urs Medical College, Kolar \\ ${ }^{3}$ Asst Professor, Dept of General Surgery, Sri Devraj Urs Medical College, Kolar \\ ${ }^{4}$ Senior Resident, Dept of General Surgery, Sri Devraj Urs Medical College, Kolar
}

\begin{abstract}
Introduction: The risk of wound infection after inguinal hernia repair depends on several factors. One of the most important factors is the preoperative skin preparation. The use of antisepsis is performed to reduce the risk of surgical site infections (SSIs) and to remove causing organisms. This work compares two different agent forms for preoperative skin preparation to prevent Surgical site infections (SSIs)

Materials and Methods: 100 adult patients were divided and randomized into two groups, each containing 50 patients. Both groups included patients that are scheduled for elective Lichtenstein inguinal hernia repair. The first group includes patients whose skin preparations were done with povidone iodine (PI) only. The second group included patients that are treated with two antiseptics; Alkosol (96\% ethanol, isopropanol-30g and ortophenilphenol- $0.1 \mathrm{~g}$ ) and povidone iodide. The povidone iodide is applied after Alkosol has evaporated. The presence of bacterial growth in the wound was determined 24 and 48 hours after operation. Swabs were used to take samples, which were then cultivated to check for bacterial growth. The presence of infection was also determined by the following criteria: pain or tenderness, induration, erythema, local warmth of the wound etc

Results: The surgeon or clinician declared that after 24 hours the wound was infected in 20 patients in the control group and in 22 patients after 48 hours. In the Alkosol (96\% ethanol, isopropanol-30g and ortophenilphenol0.1g) andpovidone iodide group infection was declared in only 3 patients after 24 hours.

Discussion: Compared to the use of providone only, the use of Alkosol (96\% ethanol, isopropanol-30g and ortophenilphenol-0.1g) and povidone iodide has many advantages and was associated with lower rates of SSIs following clean surgery. A larger trial is warranted in order to add definitive and more conclusive data to the current evidence base.

Keywords: surgical site infection; ethanol; povidone iodide; hernia repair.
\end{abstract}

\section{INTRODUCTION}

It is believed that nearly all surgical wounds are contaminated; however, infection does not develop in all operated patients. The development of infection depends mainly on the factors such as general state of the patient, their immune status and the set of contributing factors, such as, for example, age, obesity, malnutrition, chronic metabolic and endocrine diseases, anemia, hypoproteinemia, etc. 
An important predictor of wound infection is also the assessment of the general condition of patients and pre-existing disease (ASA group). If the degree of ASA $>2$, the risk of surgical site infections is increased ${ }^{(1)}$. In the context of studies on the significance of nosocomial infections in the US, the Center for Disease Control has developed a model of the four risk factors for surgical site infection: abdominal surgery, procedures that take more than two hours, surgical procedures classified as Class III (contaminated) or Class IV (dirty) and patients with three or more comorbidities at the time of discharge from hospital. The most common cause of intra-hospital infections (IHI) are bacteria. The types of bacteria that cause IHI changed over time depending on the application of antibiotics, diagnostic and therapeutic procedures. In addition, the properties of individual bacteria are responsible for their epidemiology. Staphylo-coccus species inhabit the skin and nasal mucosa. In normal circumstances they do not live in the environment and are relatively resistant to drying ${ }^{(2)}$. The important risk factors for SSI are the following: type of hernia (inguinal, incisional), operative approach (openlaparoscopic), use of prosthetic material and drainage. The cause of SSIs in elective surgery is bacteria that originally came from the skin ${ }^{(3)}$.

\section{OBJECTIVES}

Despite the implementation of preoperative preventive measures, which include skin cleansing with povidone- iodine, or other agents surgicalsite infection occurs in a significant number of patients who undergo surgery each year. The patient's skin is a major source of pathogens and it is conceivable that improving skin antisepsis would decrease surgical-site infections ${ }^{(4)}$. The main objective of this study was to compare the efficacy in prevention of surgical-site infections of $96 \%$ ethanol, isopropanol - 30g, ortophenilphenol - $0.1 \mathrm{~g}$ and povidone iodide to that of povidone iodine only. The Lichtenstein hernia repair is considered as a clean surgery operation. The causes of SSI for this type of elective surgery are bacteria that arrive from the skin ${ }^{(3)}$.

The objective of the study is to determine the frequency of wound infection after elective inguinal repair according to the preoperative site preparation

\section{MATERIAL AND METHODS:}

\section{Study Design}

We conducted this prospective, randomized clinical trial between August 2015 and February 2017 at R L Jalappa Hospital and research centre, Tamaka, Kolar, Karnataka, India. The database of all patient included in study was made.

\section{Patients}

Inclusion criteria: Patients who had an unilateral inguinal hernia repaired. The age of patients is between 18 and 65 years. The study included patients of the ASA I and ASA II category. Exclusion criteria were a history of allergies to alcohol, or iodophors; evidence of infection at or adjacent to the operative site; patient with bilateral hernia, inguinoscrotal hernia, repair without use of a polypropylene net, laparoscopic hernia repair, duration of surgery longer than two hours and the perceived inability to follow the patient's course for 10 days after surgery.

\section{Interventions}

Enrolled patients were randomly assigned in a 1:1 ratio to have one of the following preoperative skin preparations. In the first group (experimental group) the patients were prepared with the solution that contains $96 \%$ ethanol, isopropanol$30 \mathrm{~g}$ and ortophenilphenol-0.1g. The solution was left to evaporate and patients were then scrubbed and painted with an aqueous solution of $10 \%$ povidone. In the second group (control group), the patients were prepared only with an aqueous solution of $10 \%$ povidone.

All patients were monitored for the following parameters: age, sex, temperature, swelling, pain, redness and wound swab. 24 and 48 hours postoperatively, all patients had swab samples 
taken from the operative site. All patients who were included in the study were subjected to the same type of general anesthesia.

\section{Efficacy Outcomes}

The primary end point of the study was the occurrence of any surgical-site infection within 10 days after surgery. The operating surgeon became aware of which interventionhe had been assigned only after the patient was brought to the operating room. Both the patients and the site investigators who diagnosed surgical-site infection on the basis of developed criteria remained unaware of the group assignments. The wound is considered to be infected according to the following criteria that include at least one of the following: (a) presence of purulent drainage; (b) isolation of organisms from fluid/tissue of the superficial incision; (c) at least one sign of inflammation (e.g., pain or tenderness, in duration, erythema, local warmth of the wound) is present; (d) the wound is deliberately opened by the surgeon; (e) the surgeon or clinician declares the wound infected. These were classified as superficial incisional infection (which involved only skin and subcutaneous tissue but not stitch-related abscesses) and deep incisional infection (which involved deeper structure such as fascia and muscle)

\section{Clinical Assessment}

Preoperative evaluation included: medical history taking, physical examination, and routine hematologic and blood chemical laboratory tests. The surgical site and the patient's vital signs were assessed at least once a day during hospitalization and on discharge, and whenever surgical-site infection occurred. After discharge, the investigators contacted the patients to check for presence of infection. The presence of SSI was determined by investigators who were unaware of the group assignments of patients. All patients were monitored for the following parameters: age, sex, temperature, swelling, pain, redness and wound swab 24 and 48 hours postoperatively.

\section{RESULTS}

There were 94 male and 6 female patients included in the study. 2 females were in the experimental group and 2 in the control group. 48 male were in experimantal group and 46 in control group. The average duration of hospitalization was 5.94 in the control group and 5.50 in the experimental group. The difference is not statistically significant. The average duration of operation was 37.6 minutes in the control group and 38 minutes in the experimental group.

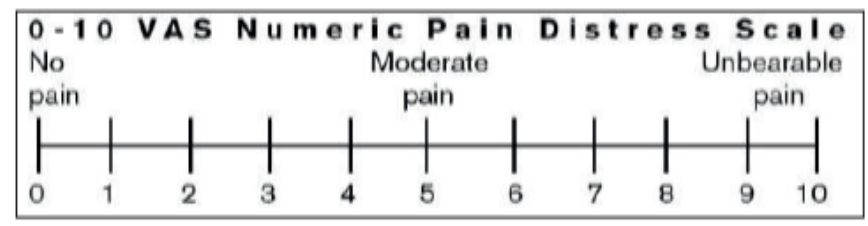

Figure 1. The visual analog scale

The average value of pain 24 hours after surgery, according to a visual analogue scale, was significantly lower in the experimental group 1.12 than in the control group 2.52. The values are also significantly lower 48 hours after surgery, 0.22 in the experimental group and 1.04 in the control group. After 24 hours swelling of the wound was noticed in 8 patients in the control group, whereas in the experimental group no swelling was evidenced. This difference is statistically signifycant ( $p<0.01$, Chi-square test). After 48 hours, swelling of the wound occurredin 10 patients in the povidone iodine group whereas in the experimental group there was no swelling (figure 2).

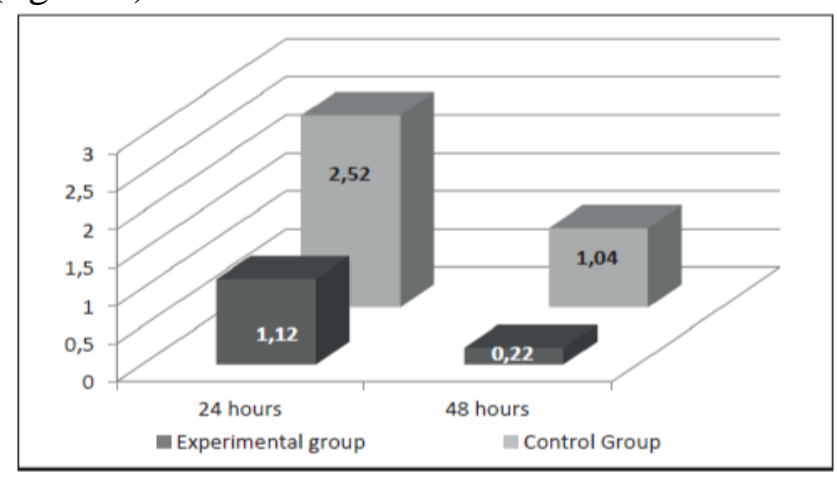

Figure 2. The average postoperative pain according to a visual analog scale in the experimental and control group 24 hours and 48 hours after surgery. 


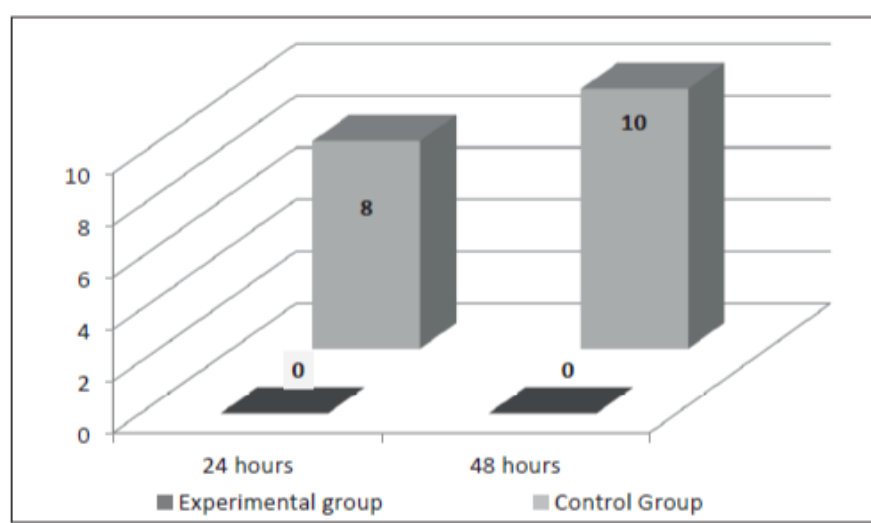

Figure 3. The postoperative wound swelling in the experimental and control group 24 hours and 48 hours after the procedure.

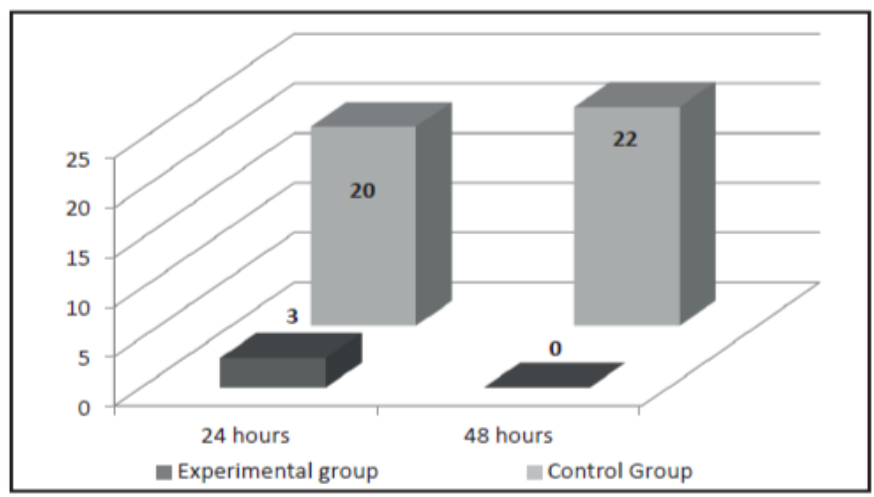

Figure 4. The redness of wound's area 24 hours and 48 hours after operation

This difference between the experimental and control group is statistically significant $(\mathrm{p}<0.01$, Chi-square test). The redness of the wound margins with or without other signs of wound infection was found in 23 patients 24 hours after operation. Only two patients were in the experimental group (6\%). In the control group redness was found in 20 patients (40\%) 24 hours after operation ( $\mathrm{p}<0.01$, Chi test).

After 48 hours hours the redness of wound margins subsided in all patients in the experimental group and in 11 patients in the control group. There were 22 patients (18\% of patients) with persistent skin redness 48 hours after operation in the control group ( $<<0,01$, Chi test). Table 1 summarizes all signs of infection according to selected criteria. There was no purulent drainage in either group. There was no need to open wound in any patient. There were no signs of major infection so we also took minor signs into consideration. These included local swelling and erythema of wound margins and warmth of wound. At least one sign should be present to declare the wound inflamed. One patient presented with uncharacteristic pain and tenderness.

\begin{tabular}{|c|c|c|c|c|}
\hline \multirow{2}{*}{$\begin{array}{l}\text { Signs of infection that were } \\
\text { followed }\end{array}$} & \multicolumn{2}{|c|}{$\begin{array}{l}\text { Control group } \\
\text { (50 patients) }\end{array}$} & \multicolumn{2}{|c|}{$\begin{array}{l}\text { Experimental } \\
\text { group, ( } 50 \mathrm{pa-} \\
\text { tients) }\end{array}$} \\
\hline & $\begin{array}{l}24 \\
\text { hours }\end{array}$ & $\begin{array}{l}48 \\
\text { hours }\end{array}$ & $\begin{array}{l}24 \\
\text { hours }\end{array}$ & $\begin{array}{l}48 \\
\text { hours }\end{array}$ \\
\hline Presence of purulent drainage; & 0 & 0 & 0 & 0 \\
\hline $\begin{array}{l}\text { Isolations of organisms from fluid/ } \\
\text { tissue of the superficial incision; }\end{array}$ & 0 & 0 & 0 & 0 \\
\hline $\begin{array}{l}\text { The wound is deliberately opened } \\
\text { by the surgeon; }\end{array}$ & 0 & 0 & 0 & 0 \\
\hline $\begin{array}{l}\text { At least one sign of inflammation } \\
\text { (e.g., pain or tenderness, indura- } \\
\text { tion, erythema, local warmth of } \\
\text { the wound) is present; }\end{array}$ & 20 & 22 & 3 & 0 \\
\hline Pain and tenderness & 1 & 0 & 0 & 0 \\
\hline Erythema of wound & 20 & 22 & 3 & 0 \\
\hline Induration (swelling) & 8 & 10 & 0 & 0 \\
\hline Warmth of the wound & 1 & 0 & 0 & 0 \\
\hline $\begin{array}{l}\text { The surgeon or clinician declares } \\
\text { the wound infected; }\end{array}$ & 20 & 22 & 3 & 0 \\
\hline
\end{tabular}

Table 1. Signs of infection according to selected criteria

In the control group there were 20 patients (40\%) with signs of infection after 24 hours and 22 patients (44\%) after 48 hours postoperatively. In the experimental group we only have 3 patients $(6 \%)$ presenting with symptoms.

\section{DISCUSSION}

Some antiseptic agents are used for cleaning intact skin, prepping patients preoperatively, prior to intramuscular injections or venous punctures, preand postoperative scrubbing in the operating room, and hand washing by medical personnel ${ }^{(6)}$. An argument for the use of antiseptics on wounds to prevent wound infection is that antiseptics may be preferable to topical antibiotics with regard to development of bacterial resistance ${ }^{(7)}$. One study found that there were fewer surgical site infections when the skin was prepared using chlorhexidine in comparison to preparation using iodine ${ }^{(7)}$. In our study we confirmed that the use of two antiseptics has a significant advantage compared to the use of only one. We presume that the effect of the alcohol solution has a shorter duration in 
preventing bacterial growth than the povidone aqueous solution and that the use of both agents could be the reason for better results. Alcohol has been used as an antiseptic for thousands of years and is still one of the best antiseptics available. Th e shorter time of antiseptic action is caused by the fast evaporation of alcohol. The povidone aqueous solution remains longer on the skin and can prevent bacterial recolonization.

Another reason for better results in the experimental group could be the timing of preoperative wound preparation. In one prospective study, 89 consecutive patients scheduled for spinal surgery were randomly allocated to 2 groups according to the patient identification numbers with their consent. In group A, povidone-iodine was applied to the surgical site just before the skin incision, after the surgeon's hands were scrubbed ${ }^{(8)}$. In group B, povidone-iodine was applied before the surgeon's hands were scrubbed. In the Group B there were significantly less patients with a positive skin culture (13 from 30 in A group and 3 from 43 in B group). From this study we can conclude that the optimal timing of preoperative skin preparation with antiseptics can play a very important role ${ }^{(8)}$. The use of two agents requires slightly more time but the improvement in the reduction of SSI a rate is quite significant. The pain after operation can be influenced by wound inflammation. In our study we found out that the pain score is related to the inflammation rate. Ethyl and isopropyl alcohol are 2 of the most effective antiseptic agents available. When used alone, alcohol is fast and short acting, has broad-spectrum antimicrobial activity, and is relatively inexpensive ${ }^{(9)}$.

We did not find any study on Medline that compares this particular combination of antiseptics. The use of Alkosol (96\% ethanol, isopropanol-30g and ortophenilphenol- $0.1 \mathrm{~g}$ ) and povidone iodide has advantages was associated with lower rates of SSIs following clean surgery than use of povidone iodide only. In our study we have shown that the use of Alkosol (96\% ethanol, isopropanol- $30 \mathrm{~g}$ and ortophenilphenol-0.1g) and povidone iodide has given considerably better results compared to the effects of using providone alone. A larger trial is warranted in order to add definitive and more conclusive data to the current evidence base. The database that can adequately collect all relevant data is very important for this kind of study. A medical database enables doctors to have better insight into the success of the treatment of individual patients and to determine whether certain methods of treatment are better than other. It is also possible to determine whether some methods are better than others on the basis of relevant data in the database that we can collect and analyze ${ }^{(10)}$.

\section{CONCLUSION}

We consider that both optimal timing of preoperative skin preparation and the choice of antiseptics play an important role in the prevention of SSIs. The combination of two antiseptics that are applied one after another could decrease SSIs rate. The time interval between the initial application of the antiseptic and the surgical incision can also be an important factor. An adequate clinical trial would give further insight into the connection. In cases of SSIs that occur in patients that underwent clean surgery the cause is usually contamination that patients acquire before hospitalization.

\section{REFERENCES}

1. Sawyer RG, Pruett TL. Wound infections. SurgClin North Am. 1994; 74(2): 519-36.

2. Custovic A, Sivic S, Ahmetagic S. Epidemiological and Microbiological Control of Hospital Infections in Surgical Patients. Med Arh.2011; 65(5): 300-3. doi:10.5455/medarh.2011.65.300-303

3. Zuvela M, Milićević M, Galun D, LekićN, Basarić D, Tomić D, PetrovićM, Palibrk I. Infection in hernia surgery. ActaChirIugosl. 2005; 9-26.

4. Kleeff J, Erkan M, Jäger C, Menacher M, Gebhardt F, Hartel M. Umbilical Microflora, Antiseptic Skin Preparation, 
and Surgical Site Infection in Abdominal Surgery. Surgical Infections. 2015;16: 450-454.

5. http://www.medscape.com/viewarticle/456 300_1, accessed January 2016.

6. http://www.medscape.com/viewarticle/456 300_1, accessed January 2016.

7. Peggy E, Lipp A, Holmes A. Preoperative skin antiseptics for preventing surgical wound infections after clean surgery. The Cochrane Library, 2004.

8. Tatsuya Y, et al. Optimal Timing of Preoperative Skin Preparation with PovidoneIodine for Spine Surgery: A Prospective, Randomized Controlled Study. Asian spine journal. 2015; 9(3): 423-6.

9. Hemani Micah L., Lepor H. Skin preparation for the prevention of surgical site infection: which agent is best?. Reviews in urology. 2009; 11(4): 190.

10. Pandza H. Minimal Data Sets for Electronic Medical Records in Hospital Settings. Acta Inform Med. 2009; 17(2): 71-3. 